\title{
Snakebites in Turkey: epidemiological and clinical aspects between the years 1995 and 2004
}

Cesaretli Y (1), Ozkan O (1)

(1) Refik Saydam Public Health Agency, Ankara, Turkey.

\begin{abstract}
The venom of poisonous snakes comprises a complex mixture of several proteins with other less significant constituents, resulting in principles capable of changing viable tissues. The hemotoxic factor is the main responsible for necrosis and tissue sloughing. Envenomations are common in rural areas of Turkey caused by snake species that present hepatotoxic venom, which causes local swelling, ecchymosis and alterations in blood profile. The epidemiological and clinical findings of snake envenomations in Turkey were evaluated based on data recorded by the National Poison Information Center (NPIC) between 1995 and 2004, in a total of 550 snakebite cases. The month of peak incidence was June (24.3\%) while most incidents occurred in Marmara, Central Anatolia and Black Sea regions of Turkey. The victims were mainly adults (54.1\%). Hospitalized patients displayed clinical signs of local (75.2\%) and systemic effects (24.7\%). Local clinical symptoms comprised edema, pain, hyperemia, numbness and ecchymosis, while systemic clinical symptoms included nausea, vomiting, hypotension, tachycardia, dyspnea, dry mouth, paresthesia, generalized edema, cyanosis and compartment syndrome. Occasionally, convulsions, confusion, loss of consciousness, hyperthermia, hepatic and circulation failure, hematoma, drowsiness, epistaxis, chest and abdominal pain, venous spasm, thrombocytopenia and bradycardia were recorded. Approximately one third (34.2\%) of the patients were treated symptomatically, while $10.5 \%$ required antivenom therapy along with symptomatic treatments and $26.3 \%$ of all patients were exclusively treated with antivenom. Although a significant number of incidents were reported, no deaths occurred. These findings emphasize the presence of multiple medically important snake species in Turkey and that public awareness and therapeutic approaches appear sufficient to manage snakebite incidents.
\end{abstract}

Key words: snakebite, envenomation, clinical features, epidemiology, Turkey.

\section{INTRODUCTION}

Snake venoms consist of a complex mixture of bioactive molecules, which present a diverse array of actions both on prey and human victims. The majority of the bioactive fraction is thought to be protein in nature. Toxic proteins and peptides in venoms are presumed to be defensive tools, immobilizing prey and aiding in the digestion process (1). Unlike medically important scorpions, that comprise about
20 species throughout the globe, venomous snakes are more numerous and widespread (2). Snakebites lead to significant medical, social and economic problems in several tropical and subtropical countries (3). Envenomations by snakebites constitute an important health problem that is not fully addressed in numerous countries (4). The incidence and frequency of snakebites vary in different geographic regions depending on several factors including climate, ecological parameters, biodiversity, distribution 
of venomous snakes, human population density, economic activities, and types of dwellings $(3,5)$.

Turkey encompasses a wide range of geographically distinct regions and a large number of medically important snake species have been reported in the country (6). Specifically, the most abundant species in Turkey belong to the following families: Acrochordidae, Viperidae, Elapidae and Colubridae (6-8). In rural areas, snake envenomations are mainly associated with members of the Viperidae family $(9,10)$.

The aim of the present study was to classify and characterize snakebites reported to the National Poison Information Center (NPIC) between 1995 and 2004, regarding epidemiology and clinical symptomatology.

\section{PATIENTS AND METHODS}

\section{Geographic Area}

The countries that border Turkey are Iraq, Iran and Syria on the southeast, Armenia and Georgia on the east and Greece and Bulgaria on the west (11). Records of snake envenomation cases were obtained from throughout the country. Turkey provinces are organized into seven censusdefined regions for statistical purposes.

\section{Data Collection}

NPIC, created in 1986, is accessible 24 hours a day, 7 days a week. Clinicians in Turkey that treat snakebite victims are required to report these accidents to NPIC. In the current study, only cases involving snake envenomations available in NPIC database and recorded between 1995 and 2004 were investigated.

\section{Epidemiological and Clinical Data}

As aforementioned, metadata were obtained from NPIC. Patients were classified according to age, gender, incident date, geographic area, admission to healthcare facilities, clinical symptoms (local and systemic), general condition and therapeutic approach.

\section{Clinical Classification of Cases}

Clinical classification was based on recordings submitted by local physicians. Patients were divided into two major groups according to their symptoms. The local envenomation group included victims that presented local pain, hyperemia, burning and itching, while symptoms of the systemic envenomation group comprised ecchymosis, nausea, vomiting, hypotension, paresthesia and generalized edema among others. Meta data on clinical symptoms, administered therapeutic interventions including antivenom administration and other agents were analyzed. Within this group patients were subdivided to groups of moderate and severe envenomation. Moderate envenomation patients had mostly local and some systemic effects including sweating,

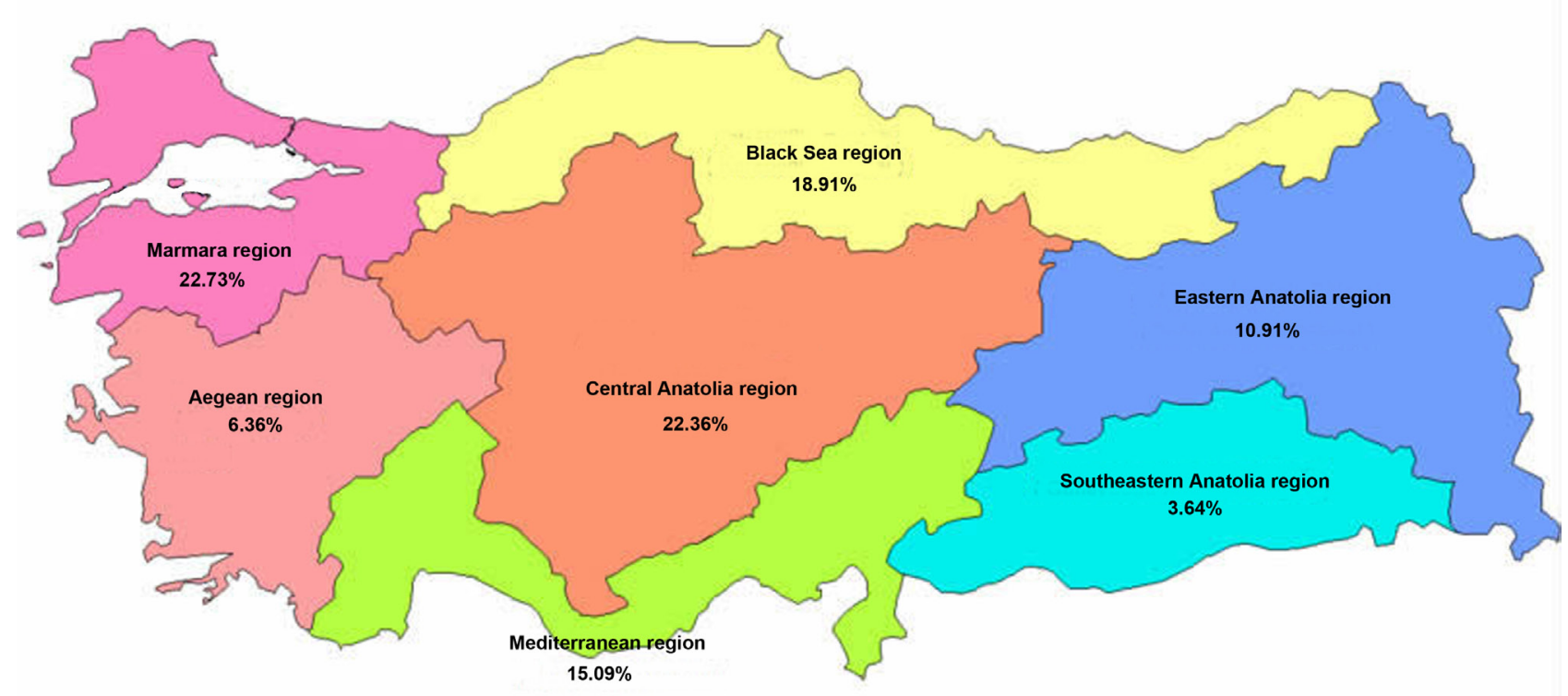

Figure 1. Distribution of snakebites according to the geographic regions of Turkey. 


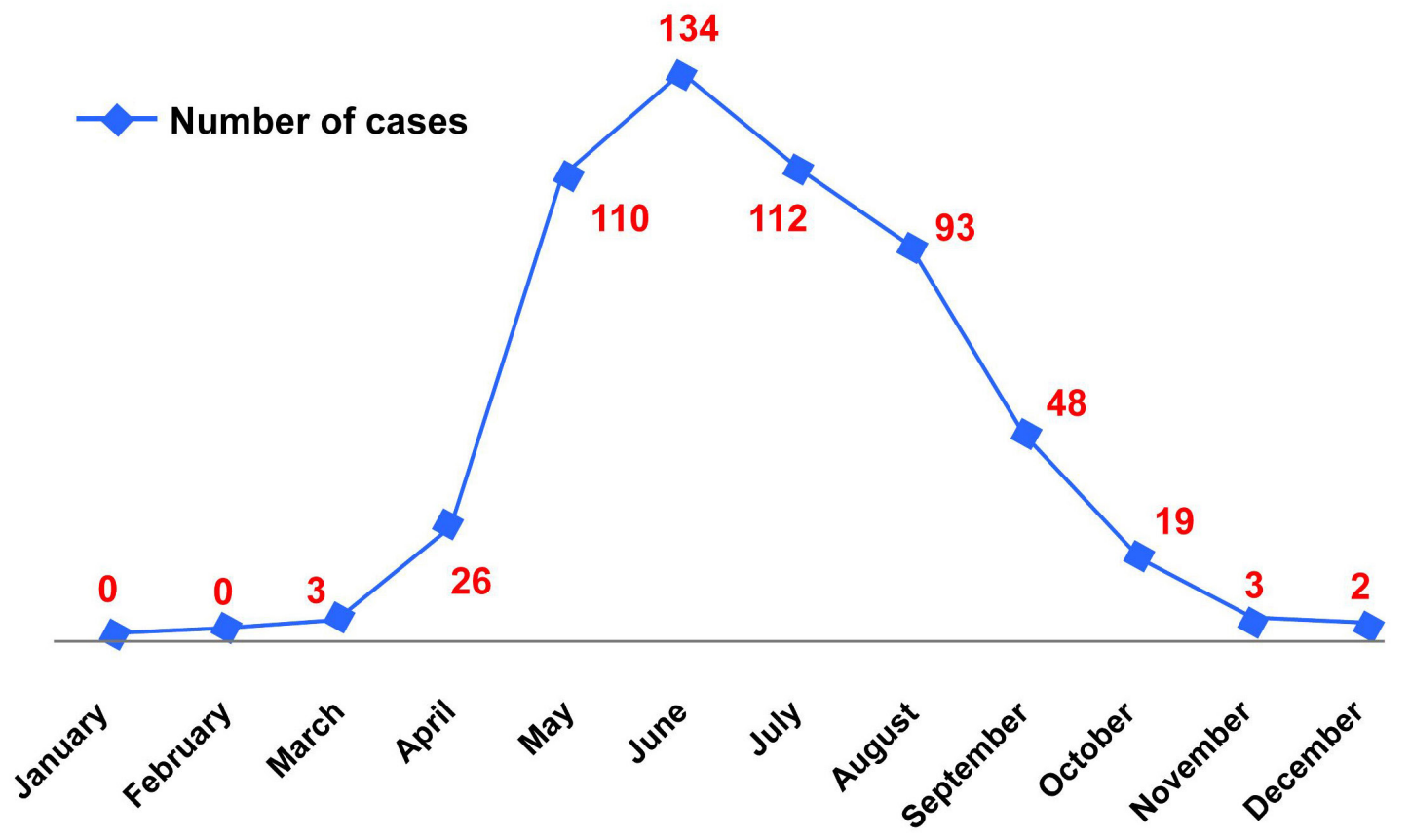

Figure 2. Distribution of snakebites according to months.

Table 1. Distribution of snakebites according to epidemiological characteristics of patients

\begin{tabular}{|c|c|c|}
\hline $\begin{array}{l}\text { Epidemiological } \\
\text { characteristics }\end{array}$ & $\begin{array}{c}\text { Number of } \\
\text { patients } \\
(\mathrm{n}=550)\end{array}$ & $\%$ \\
\hline \multicolumn{3}{|c|}{ Age (years) } \\
\hline$\leq 4$ & 27 & 4.91 \\
\hline $5-9$ & 56 & 10.18 \\
\hline $10-19$ & 100 & 18.18 \\
\hline $20-29$ & 119 & 21.64 \\
\hline $30-39$ & 101 & 18.37 \\
\hline $40-49$ & 63 & 11.45 \\
\hline $50-59$ & 38 & 6.91 \\
\hline $60-69$ & 28 & 5.09 \\
\hline$\geq 70$ & 7 & 1.27 \\
\hline Unknown & 11 & 2 \\
\hline \multicolumn{3}{|c|}{ Gender } \\
\hline Male & 302 & 54.91 \\
\hline Female & 234 & 42.55 \\
\hline Unknown & 14 & 2.54 \\
\hline \multicolumn{3}{|c|}{ Time elapsed until admission (hours) $(n=411)$} \\
\hline$\leq 1$ & 178 & 43.31 \\
\hline $1-2$ & 53 & 12.90 \\
\hline $2-3$ & 22 & 5.35 \\
\hline$\geq 4$ & 158 & 38.44 \\
\hline \multicolumn{3}{|c|}{ Admission center } \\
\hline Local hospital & 526 & 95.63 \\
\hline Private medical center & 17 & 3.1 \\
\hline Primary health center & 5 & 0.91 \\
\hline Others & 2 & 0.36 \\
\hline
\end{tabular}

nausea, vomiting, dry mouth, tachycardia, dyspnea, hypotension, drowsiness. Severe envenomation patients displayed systemic effects such as generalized edema, cyanosis, convulsions and confusion.

\section{RESULTS}

From 1995 to 2004, 129,548 envenomation cases of various origins were reported in Turkey, of this total 1,929 involved animal bites or stings, of which 550 comprised snakebites.

\section{Epidemiological Data}

The reports of snakebites were from all Turkish regions. The ratio of incidents per geographic region is presented in Figure 1 (in percent). Snakebites were more frequent in the northwest region, also known as Marmara $(\mathrm{n}=125)$, followed by Central Anatolia region $(n=123)$ and Black Sea region $(n=104)$. Marmara, despite its relatively small territory ( $8.5 \%$ of Turkey), is the most densely populated region of the country.

Accidents were more common during the summer $(61.6 \%)$. The monthly distribution of snakebites is graphically demonstrated in Figure 2 , showing a clear peak in early summer with $24.3 \%$ of the incidents occurring in June.

The affected population had a male/female ratio of 1.29. Age distribution of victims is 

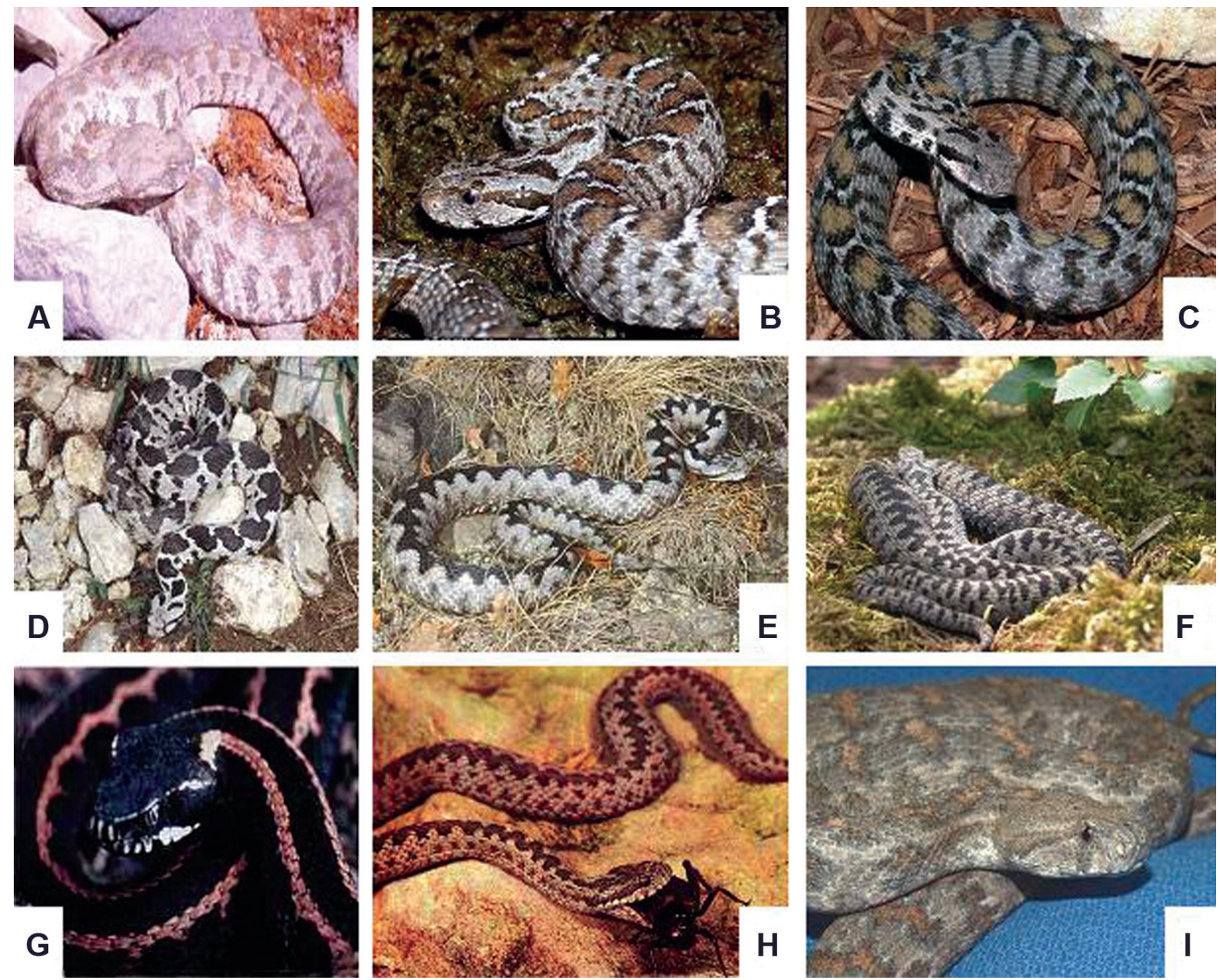

Figure 3. (A) Macrovipera lebetina, (B) Montivipera albizona, (C) Montivipera wagneri, (D) Montivipera xanthina, (E) Vipera ammodytes, (F) Vipera barani, (G) Vipera kaznakovi, (H) Vipera anatolica (V. ursinii anatolica), (I) Vipera pontica. M. lebetina and M. xanthina are the most common venomous snakes in south and southeastern Anatolia.

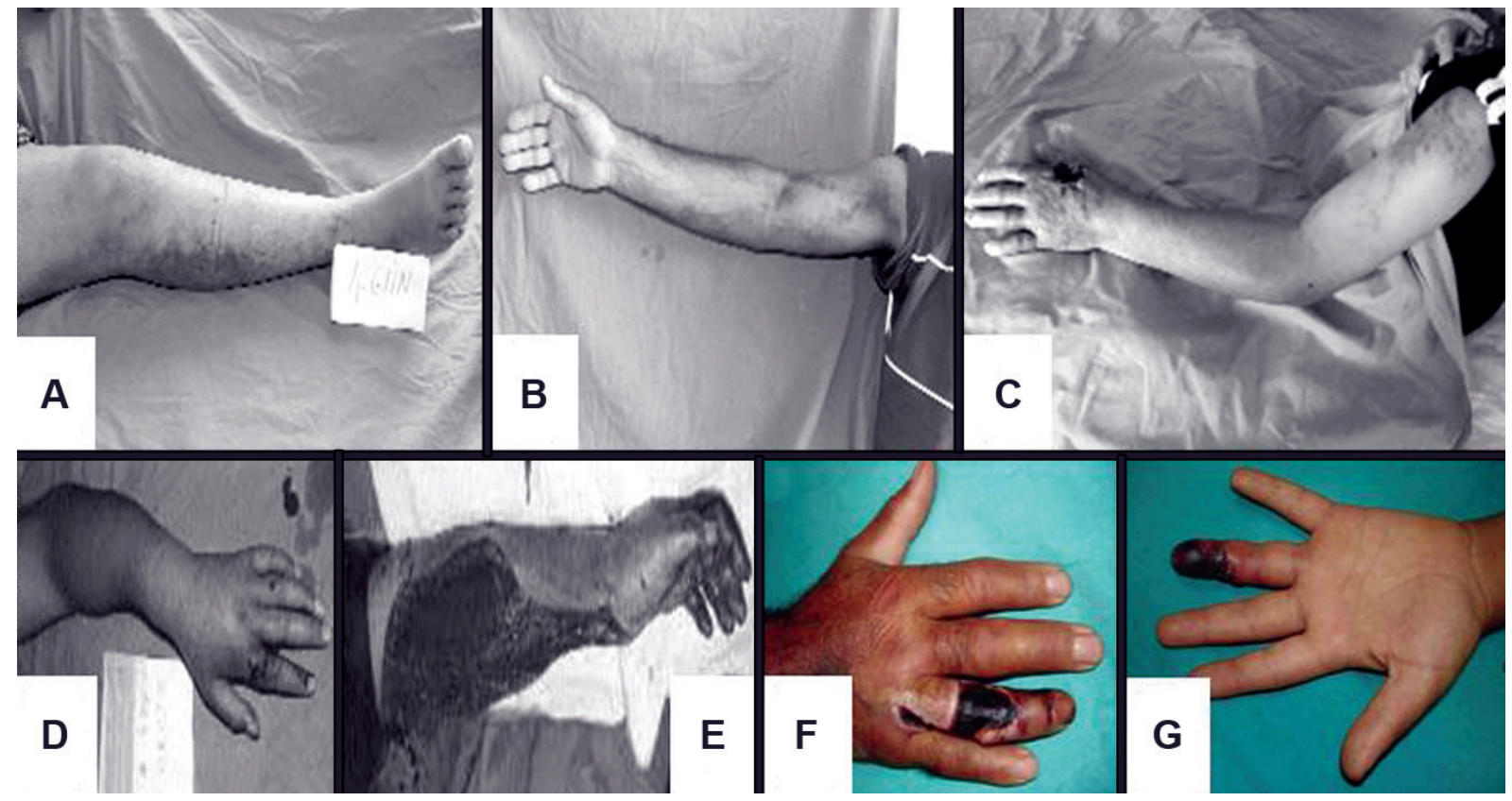

Figure 4. Common effects of snakebites in humans: (A) edema on the leg, (B) ecchymosis, (C) necrosis, (D) edema on the hand, $(E)$ fasciotomy on the arm, $(F$ and $G)$ necrosis. 
Table 2. Clinical manifestations in patients

\begin{tabular}{|c|c|c|}
\hline Clinical symptoms & $\begin{array}{c}\text { Number of } \\
\text { patients } \\
(n=105)\end{array}$ & $\%$ \\
\hline Local symptoms & 79 & 75.24 \\
\hline Edema & 45 & 42.86 \\
\hline Pain & 32 & 30.48 \\
\hline Hyperemia & 30 & 28.57 \\
\hline Numbness & 5 & 4.76 \\
\hline Sensitiveness & 2 & 1.90 \\
\hline Burning & 1 & 0.95 \\
\hline Itching & 1 & 0.95 \\
\hline Compartment syndrome & 1 & 0.95 \\
\hline Systemic symptoms & 26 & 24.76 \\
\hline Ecchymosis & 8 & 7.62 \\
\hline Nausea & 7 & 6.66 \\
\hline Vomiting & 7 & 6.66 \\
\hline Hypotension & 4 & 3.81 \\
\hline Paresthesia & 2 & 1.90 \\
\hline Generalized edema & 2 & 1.90 \\
\hline Tachycardia & 2 & 1.90 \\
\hline Dyspnea & 2 & 1.90 \\
\hline Cyanosis & 2 & 1.90 \\
\hline Lethargy & 2 & 1.90 \\
\hline Dry mouth & 2 & 1.90 \\
\hline Hyperthermia & 1 & 0.95 \\
\hline Bradycardia & 1 & 0.95 \\
\hline Venous spasm & 1 & 0.95 \\
\hline Circulation failure & 1 & 0.95 \\
\hline Hematoma & 1 & 0.95 \\
\hline Loss of consciousness & 1 & 0.95 \\
\hline Epistaxis & 1 & 0.95 \\
\hline Chest pain & 1 & 0.95 \\
\hline Drowsiness & 1 & 0.95 \\
\hline Abdominal pain & 1 & 0.95 \\
\hline Liver failure & 1 & 0.95 \\
\hline Confusion & 1 & 0.95 \\
\hline Convulsion & 1 & 0.95 \\
\hline Thrombocytopenia & 1 & 0.95 \\
\hline
\end{tabular}

Clinical assessment of envenomation $(n=105)$

\begin{tabular}{c|c|c}
\hline Non-envenomation & 3 & 2.86 \\
\hline Mild envenomation & 34 & 32.38 \\
\hline Moderate envenomation & 56 & 53.33 \\
\hline Severe envenomation & 12 & 11.43 \\
\hline
\end{tabular}

\begin{tabular}{c|c|c|}
\hline \multicolumn{3}{|c|}{ Treatment $(\mathbf{n}=\mathbf{7 6})$} \\
\hline $\begin{array}{c}\text { Symptomatic } \\
\text { antivenomom }\end{array}$ & 26 & 34.21 \\
\hline Antivenom & 8 & 10.53 \\
\hline Others & 20 & 26.31 \\
\hline
\end{tabular}

displayed in Table 1, with the age group from 20 to 29 years old (21.6\% of all patients) being the most afflicted. The majority of the victims (95.6\%) arrived at local healthcare facilities or hospitals in less than one hour after the snakebite (Table 1).

\section{Clinical Assessment of Envenomation and Treatment}

Figure 3 presents the snake species mostly responsible for human envenomations in Turkey whereas Figure 4 displays clinical manifestations of the victims. Table 2 shows that local symptoms of envenomation were observed in $75.2 \%$ of the victims, including local edema (42.8\%), local pain $(30.4 \%)$, hyperemia (28.5\%), and numbness (4.7\%). Regarding systemic symptoms, the most frequent findings were: ecchymosis (7.6\%); nausea and vomiting (6.6\%); hypotension (3.8\%); and paresthesia, generalized edema, tachycardia, dyspnea, cyanosis and dry mouth (1.9\%). Occasionally convulsions, confusion, loss of consciousness, hyperthermia, hepatic failure and circulation failures, hematoma, drowsiness, epistaxis, chest and abdominal pain, venousspasm, thrombocytopenia and bradycardia $(0.9 \%)$ were also observed. Most incidents involved moderate envenomation (53.3\%), followed by mild (32.3\%) and severe envenomation (11.4\%), as shown in Table 2. Treatment was based on symptomatic measures (34.2\%), symptomatic approach with antivenom support (10.5\%) and antivenom only (26.3\%).

\section{DISCUSSION}

Up to our knowledge, the present work is the first epidemiological and clinical study on snake envenomation covering all geographic regions of Turkey. Analyzed NPIC records showed a total number of 550 snakebite cases during from 1995 to 2004. Interestingly, in the southeast region, the number of snakebite incidents was low compared to venomous scorpion stings (12). Turkey has presents subtropical and semi-arid climates with extreme temperature range. Moreover, precipitation varies significantly from one region to another in the country (11). Thus, it is difficult to correlate geographic features with reported snake envenomations. However, most bites by Vipera species occurred in rural areas (13).

In Turkey, the most venomous snakes belong to the Acrochordidae and Viperidea families, 
which include the following species: M. lebetina, M. albizona, M. wagneri, $M$. xanthina, $M$. bulgardaghica, V. ammodytes, V. barani, V. berus, $V$. kaznakovi, V. pontica, V. raddei, V. darevskii, $V$. anatolica and $V$. eriwanensis (Figure 3). Additionally, other species from the Colubridae family were also classified as medically important in Turkey, such as Malpolon monspessulanus, Telescopus fallax and Telescopus nigriceps $(6,14-$ 16).

Corroborating the literature from several countries, we found that the frequency of snakebites is higher in warmer periods of the year, peaking in June $(2,14,17,18)$. This is not surprising, since snakes are more active during warm seasons. Also consistent with previous reports, in our study males (54.9\%) and young adults $(40 \%)$ were more affected by envenomations $(5,13,14,17-19)$. An interesting observation in the current study was that almost all patients (95\%) actively sought medical help and a significant fraction (43.3\%) reached a healthcare facility in less than one hour after the bite, which indicates that the population is aware of the serious consequences of snake envenomations.

The severity of venomous snakebites depends on several factors, including the bite site, the amount of injected venom, and the effectiveness of the initial therapy (20). For instance, Vipera venom possesses a variety of biological activities, and once it is injected into an animal, it may reach the bloodstream within a minute, so that its components must achieve their effects at very low concentrations $(20,21)$.

Snake venoms may exhibit both anticoagulant and procoagulant activities that might lead to concurrent thrombosis, bleeding disorders and disseminated intravascular coagulation. In addition, their toxins can produce edema, vasoconstriction, and tissue necrosis due to both direct cellular destruction and vascular injury around the bite site $(8,20,21)$.

Usually, local symptoms of snakebites comprise swelling (generally within two hours), pain, soreness of regional lymph nodes, bruises and necrosis on the bite site, as well as occasionally development of compartment syndrome $(9,10$, 20). In the current work, the manifestations of snake envenomations included local symptoms such as edema, local pain, hyperemia, numbness and compartment syndrome.
In Turkey, systemic symptoms of snake envenomations previously reported consisted of: epistaxis; hematemesis; ecchymosis; hemoptysis; subconjunctival, retroperitoneal and intracranial hemorrhages; ptosis; weakness; paresthesia; dysphagia; sweating; respiratory depression; paralysis; myotoxicity related symptoms; disseminated intravascular coagulation; and acute renal failure $(8,10,13,18,20-26)$ (Figure 4).

In the present study, systemic symptoms comprised: nausea; vomiting; hypotension; paresthesia; generalized edema; tachycardia; dyspnea; cyanosis; lethargy; dry mouth; ecchymosis; hematoma; circulation and hepatic failures; confusion; convulsions and thrombocytopenia. These findings strongly indicate that most envenomations result in hematological, neurotoxic, and myotoxic complications.

In our work, which corroborates an earlier report, $32.38 \%$ of the envenomation cases were classified as mild, 53.33\% were moderate, and only less than 5\% were considered severe (19).

The specific treatment for envenomations due to snakebites is the administration of speciesspecific antivenom, which is widely employed in countries where snake attacks are frequent. There are three different antivenoms available in Turkey: European Viper Venom (Intervax Biological, Canada) - a polyvalent antivenom against $V$. ammodytes, V. aspis, V. berus, V. lebetina, V. ursinii and $V$. xanthina venoms - is the most frequently used in the country; Pasteur Ipser Europe ${ }^{\circledast}$ (Pasteur Merieux, France) - a polyvalent antivenom against V. aspis, V. ammodytes and V. berus venoms - is also highly effective against several toxins; and finally, Polyvalent Snake Venom Antiserum ${ }^{\circledR}$ (Vacsera, Egypt) against $V$. ammodytes, $V$. lebetina and $V$. xanthina venoms) $(14,20)$. Moreno et al. (19) reported that $16 \%$ of the patients affected by snake envenomations required antivenom treatment. In another study, antivenom was administered in 17 out of 24 patients (14). In the present work, a significant number of patients was treated with antivenom (36\%).

\section{CONCLUSIONS}

The epidemiological and clinical characteristics of snake envenomations throughout Turkey, between 1994 and 2005, were herein reported. These data clearly indicate that there are multiple 
species of medically important venomous snakes in the country. The findings also permit the comparison among cases of snake envenomations in different countries or regions, as well as the assessment of other types of accidents with poisonous animals, including scorpionism and marine envenomations. Based on our knowledge, it is evident that public awareness campaigns in Turkey and the increased number of healthcare facilities have kept to a minimum lethality due to envenomations. Furthermore, the offer of sufficient quantities of good quality antivenom to medical facilities in both rural and urban areas is crucial, as well as the maintenance of an adequate number of trained medical professionals in regions where snake envenomations are most common.

\section{ACKNOWLEDGMENTS}

We wish to thank Juliana Simionato for her valuable comments and high quality editing on this manuscript.

\section{COPYRIGHT}

(c) CEVAP 2010

\section{SUBMISSION STATUS}

Received: February 5, 2010.

Accepted: June 24, 2010.

Abstract published online: August 13, 2010.

Full paper published online: November 30, 2010.

\section{CONFLICTS OF INTEREST}

There is no conflict.

\section{CORRESPONDENCE TO}

OZCAN OZKAN, Refik Saydam Public Health Agency, 06100 Ankara, Turkey. Phone: 0090312 49821 50. Email: ozcanozkan_62@hotmail.com.

\section{REFERENCES}

1. Queiroz GP, Pessoa LA, Portaro FCV, Furtado MD, Tambourgi DV. Interspecific variation in venom composition and toxicity of Brazilian snakes from Bothrops genus. Toxicon. 2008;52(8):842-51.

2. Brunda G, Sashidhar RB. Epidemiological profile of snake-bite cases from Andhra Pradesh using immunoanalytical approach. Indian J Med Res. 2007;125(5):661-8.

3. Krifi MN, Marrakchi N, El Ayeb M, Dellagi $\mathrm{K}$. Effect of some variables on the in vivo determination of scorpion and viper venom toxicities. Biologicals. 1998;26(4):277-88.
4. Maretic Z. Some clinical and epidemiological problems of venom poisoning today. Toxicon. 1982;20(1):345-8.

5. Otero-Patino R. Epidemiological, clinical and therapeutic aspects of Bothrops asper bites. Toxicon. 2009;54(7):998-1011.

6. Arikan H, Göçmen B, Kumlutaş Y, Alpagut KN, Ilgaz Ç, Yıldız MU. Electrophoretic characterisation of the venom samples obtained from various Anatolian snakes (Serpentes: Colubridae, Viperidae, Elapidae). N West J Zool. 2008;4(1):16-28.

7. Arikan H, Göçmen B, Mermer A, Bahar H. An electrophoretic comparison of the venoms of a colubrid and various viperid snakes from Turkey and Cyprus, with some taxonomic and phylogenetic implications. Zootaxa. 2005;1038:110 .

8. Göçmen B, Arikan H, Ozbel Y, Mermer A, Cicek K. Clinical, physiological and serological observations of a human following a venomous bite by Macrovipera lebetina lebetina (Reptilia: Serpentes). Acta Parasitol Turcica. 2006;30(2):158-62.

9. Okur MI, Yildırım AM, Köse R. Venomous snake bites and its therapy in Turkey. T Klin J Med Sci. 2001;21:528-32.

10. Köse R. The management of snake envenomation: evaluation of twenty-one snake bite cases. Ulus Travma Acil Cerrahi Derg. 2007;13(4):307-12.

11. Turkish State Meteorological Service [homepage on the Internet]. Available from: http://www.dmi. gov.tr/index.aspx.

12. Adiguzel S, Ozkan O, Inceoglu B. Epidemiological and clinical characteristics of scorpionism in children in Sanliurfa, Turkey. Toxicon. 2007;49(6):875-80.

13. Ertem K, Esenkaya I, Kaygusuz MA, Turan C. Our clinical experience in the treatment of snakebites. Acta Orthop Traumatol Turc. 2005;39(1):54-8.

14. Bulut M, Eren F, Ozdemir F, Koksal O, Durmus O, Esen M, et al. Snakebite cases admitted to Uludag University Faculty of Medicine Emergency Department and current management of snake bite. Akademik Acil Tip Dergisi. 2009;8(1):30-4.

15. World Health Organization. Progress in the characterization of venoms and standardization of antivenoms. Geneva: WHO;1981. WHO Offset Publications No. 58. Available from: http:// whqlibdoc.who.int/offset/WHO_OFFSET_58. pdf.

16. Chippaux JP. Snake-bites: appraisal of the global situation. Bull World Health Organ. 1998;76(5):515-24.

17. Currie BJ. Snakebite in tropical Australia: A prospective study in the "Top End" of the 
Northern Territory. MJA. 2004;181(11-12):693-7.

18. Tinoco HB, Norberg AN, Pile E, Carvalho CRP, Silva DA, Guerra-Sanches F. Snake envenomations in Northwest countries of the Rio de Janeiro State, Brazil. J Venom Anim Toxins incl Trop Dis. 2005;11(1):34-8.

19. Moreno E, Queiroz-Andrade M, Lira-da-Silva RM, Tavares-Neto J. Clinical and epidemiological characteristics of snakebites in Rio Branco, Acre. Rev Soc Bras Med Trop. 2005;38(1):15-21.

20. Bozkurt M. Kulahci K, Zor F, Kapi E. The management of pit viper envenomation of the hand. HAND. 2008;3(4):324-31.

21. Aroch I, Yas-Natan E, Kuzi S, Segev G. Haemostatic abnormalities and clinical findings in Vipera palaestinae envenomed dogs. Vet J. 2010;185(2):180-7.
22. Buyukbebeci O, Barlas SK, Karakurum G, Gulec A, Demir S. Yilan isırıklarında klinik deneyimlerimiz. Artroplasti Artroskopik Cerrahi. 2001;12(1):47-9.

23. Ertem K. Venomous snake bite in Turkey. Eur J Gen Med. 2004;1(4):1-6.

24. Satar S, Karcioglu O, Sebe A. An unusual localization of snakebite treated without antivenin: case report. Mt Sinai J Med. 2005;72(2):116-9.

25. Yüksel A, Ergin E, Barışık V. Development of acute renal failure and disseminated intravascular coagulation after snakebite. F U Sağ Bil Tip Derg. 2009;23(1):37-9.

26. Demir C, Atik B, Dilek I. Dissemine intravascular coagulation and multiple organ dysfunction following snake bite: a report of two cases. Van Tip Dergisi. 2005;12(1):22-5. 